\title{
Antiretroviral treatment initiation does not differentially alter neurocognitive functioning over time in youth with behaviorally acquired HIV
}

\author{
Sharon L. Nichols ${ }^{1}$. James Bethel ${ }^{2} \cdot$ Bill G. Kapogiannis ${ }^{3} \cdot$ Tiandong $\mathbf{L i}^{2}$ • \\ Steven P. Woods ${ }^{4}$ - E. Doyle Patton ${ }^{5}$ - Weijia Ren ${ }^{2} \cdot$ Sarah E. Thornton ${ }^{2}$. \\ Hanna O. Major-Wilson ${ }^{6}$ • Ana M. Puga ${ }^{5}$. John W. Sleasman ${ }^{7}$ • Bret J. Rudy ${ }^{8}$. \\ Craig M. Wilson ${ }^{9}$ Patricia A. Garvie ${ }^{5}$ and the Adolescent Medicine Trials Network for \\ HIV/AIDS Interventions
}

Received: 11 May 2015 /Revised: 18 September 2015 /Accepted: 21 September 2015 / Published online: 13 October 2015

(C) The Author(s) 2015. This article is published with open access at Springerlink.com

\begin{abstract}
Although youth living with behaviorally acquired HIV (YLWH) are at risk for cognitive impairments, the relationship of impairments to HIV and potential to improve with antiretroviral therapy (ART) are unclear. This prospective observational study was designed to examine the impact of initiation and timing of ART on neurocognitive functioning in YLWH in the Adolescent Medicine Trials Network for HIV/ AIDS Interventions. Treatment naïve YLWH age 18-24 completed baseline and four additional assessments of attention/ working memory, complex executive, and motor functioning over 3 years. Group 1 co-enrolled in an early ART initiation study and initiated ART at enrollment CD4 $>350(n=56)$; group 2 had CD4 $>350$ and were not initiating ART $(n=66)$; group 3 initiated ART with CD4 $<350(n=59)$ per standard of care treatment guidelines at the time. Treatment was deintensified to boosted protease inhibitor monotherapy at 48 weeks for those in group 1 with suppressed viral load.
\end{abstract}

Portions of the research described herein were presented at the network meeting of the Adolescent Trials Network for HIV/AIDS Interventions in Bethesda, Maryland in October, 2014, and at the Conference on Retroviruses and Opportunistic Infections in Seattle, Washington, in February, 2015.

Sharon L. Nichols

slnichols@ucsd.edu

1 Department of Neurosciences, University of California, 9500 Gilman Drive, \#0935, La Jolla, San Diego, CA 92093, USA

2 Westat, Rockville, MD, USA

3 National Institutes of Health, Bethesda, MD, USA

4 Department of Psychiatry, University of California, La Jolla, San Diego, CA, USA
Covariates included demographic, behavioral, and medical history variables. Analyses used hierarchical linear modeling. All groups showed improved performance with peak at 96 weeks in all three functional domains. Trajectories of change were not significantly associated with treatment, timing of treatment initiation, or ART de-intensification. Demographic variables and comorbidities were associated with baseline functioning but did not directly interact with change over time. In conclusion, YLWH showed improvement in neurocognitive functioning over time that may be related to practice effects and nonspecific impact of study participation. Neither improvement nor decline in functioning was associated with timing of ART initiation or therapy de-intensification.

Keywords HIV · Neurocognitive functioning · Adolescent . Youth $\cdot$ Antiretroviral therapy $\cdot$ HIV-associated neurocognitive disorder
Children's Diagnostic \& Treatment Center, Inc., Ft. Lauderdale, FL, USA

6 Department of Pediatrics, University of Miami, Miami, FL, USA

7 Division of Allergy and Immunology, Duke University, Durham, NC, USA

8 Department of Pediatrics, New York University, New York, NY, USA

9 Department of Epidemiology, University of Alabama at Birmingham, Birmingham, AL, USA 


\section{Introduction}

Recent US guidelines call for all individuals with HIV infection to initiate antiretroviral therapy (Thompson et al. 2012) (ART) upon diagnosis, with prevention of central nervous system (CNS) sequelae serving as one argument for early initiation (Ellis et al. 2011). Despite ART having diminished the most severe CNS sequelae of HIV, subtle neurocognitive impairment continues to be a concern even for those on ART (Heaton et al. 2011). A meta-analysis found robust but modest positive effects of ART on HIV-associated cognitive dysfunction in adults (Al-Khindi et al. 2011). However, few studies have focused on individuals earlier in infection; while studies suggest a significant impact of acute HIV infection on the CNS is due to chronic inflammation that is independent of viral replication (Ancuta et al. 2008), it could be argued that control of viral replication by early ART may protect the CNS. Furthermore, late adolescents and young adults (hereafter referred to as "youth") have received less focus in studies of ART and neurocognition, despite being a population at high risk for HIV and demonstrating relatively high rates of neurocognitive impairment (Nichols et al. 2013). Reservations regarding ART initiation in youth, including poor adherence resulting in emergence of drug resistant virus and toxicity associated with long-term treatment (Gagliardo et al. 2013; Lee et al. 2014), call for studies demonstrating neurocognitive benefit or at least lack of harm associated with ART in youth.

In 2007, the Adolescent Medicine Trials Network for HIV/ AIDS Interventions (ATN) began enrollment for ATN 061, a prospective 3-year randomized clinical trial to study the immunological impact for youth of initiating highly active antiretroviral therapy (HAART) early (CD4+ T cell (CD4) counts $>350$ cells $/ \mathrm{mm}^{3}$ ) compared to delaying treatment until concurrent treatment guidelines were met. This study also examined the effect of treatment de-intensification to boosted protease inhibitor (PI)-monotherapy among participants who achieved sustained viral suppression. The current study, ATN 071, was a 3-year prospective observational study designed to assess changes in neurocognitive functioning associated with early HAART initiation. The study included ATN 061 participants, additional untreated youth, and a group initiating ART per standard of care (SOC). Analysis of baseline data for ATN 071 demonstrated that $66 \%$ of participants qualified for a diagnosis of HIV-associated neurocognitive disorder (Antinori et al. 2007) (HAND) at baseline, with impairments occurring most commonly in memory and learning, executive functioning, and fine motor speed (Nichols et al. 2013). Significant associations of some neurocognitive measures with CD4 count suggested possible subtle effects of HIV on neurocognition. Presented herein are longitudinal analyses of neurocognitive functioning over 3 years to determine whether ART, timing of ART initiation, and treatment deintensification were associated with differences in the trajectory of neurocognitive functioning over time in ATN 071 while accounting for adherence and important confounding variables. The findings follow up the cohort described in Nichols et al. 2013 and represent the first study of the impact of ART on neurocognitive functioning among a key population affected by the HIV epidemic, late adolescents and emerging adults.

\section{Methods}

\section{Participants}

Youth aged 18-24 years with behaviorally acquired HIV infection were enrolled from 15 ATN and 5 International Maternal Pediatric Adolescent AIDS Clinical Trials sites across the USA and Puerto Rico. At the time of enrollment, the US Department of Health and Human Services Guidelines for the Use of Antiretroviral Agents in Adults and Adolescents (Guidelines) recommended starting ART in patients with CD4 cells $<350$, in absence of contraindications. Recruitment, participants, and assessment methodology are described in Nichols et al. 2013, with essential details repeated herein for convenience. Participants enrolled into four groups. Two groups had CD4 $>350$ at baseline: group 1 participants had been randomized to initiate early ART upon enrollment in ATN 061, while group 2 deferred ART until SOC guidelines for ART initiation were met. Group 3 participants met Guidelines for ART initiation with CD4 $<350$ at enrollment and started treatment. Group 4 (CD4 $<350$ and not initiating ART) was seen only at baseline and not discussed herein. Participants co-enrolled in ATN 061 were required to have HIV-1 RNA viral load $(\mathrm{VL})>1000$ copies $/ \mathrm{mm}^{3}$. All participants were treatment-naïve except for ART to prevent mother-to-child HIV transmission (PMTCT; $n=3$ ) with total duration of ART $<6$ months. Fluency in English or Spanish was required. Exclusion criteria included prior ART experience other than for PMTCT, current pregnancy, active substance use judged likely to interfere with meeting study requirements, psychosis, or significant non-HIV-related cognitive or motor impairment (e.g., cerebral palsy, severe traumatic brain injury; milder comorbidities including learning disabilities and attention-deficit/hyperactivity disorder were allowed). Participants who became pregnant while on study were discontinued due to potential impact of pregnancy on treatment considerations and cognition. The study was approved by Institutional Review Boards at all participating institutions; participants provided written informed consent in accordance with institutional requirements prior to enrollment. 


\section{Study evaluations}

Neurocognitive and behavioral functioning Study design and evaluations are described elsewhere (Nichols et al. 2013). Participants were followed for 144 weeks, completing study evaluations at baseline and weeks 24, 48, 96, and 144.

The assessment battery included domains with previously demonstrated sensitivity to HAND in adults (Table 1), including memory, motor skills, attention, and complex executive functions. Standard scores using published normative data, with adjustments for age and, where available, race, Hispanic ethnicity, education and/or gender, were computed. Scores within domains were converted to $z$-scores and averaged for analytic clarity and to reduce the number of regression analyses performed. Neurocognitive measures were grouped into two sets: a monitoring battery conducted at all time points and a second set of measures administered only at baseline and exit (Table 1). Analyses reported herein focus on three scales derived from the monitoring battery reflecting attention, motor functioning, and complex executive functioning; individual tests were combined into domain scores to reduce the number of analyses required (Nichols et al. 2013). The domains included in the monitoring battery were selected based on anticipated sensitivity to change (Al-Khindi et al. 2011).

Additional measures of depression, psychiatric distress, substance use, and medication adherence were administered for use as covariates in analyses. In addition, participants were asked whether they use potentially psychoactive substances (street drugs or medications; PPS), and whether they used them on the day of testing.

Demographics and psychosocial history Participants reported birth sex, race, ethnicity, primary language, sexual orientation, employment, school enrollment status, past 30-day income, educational attainment, and educational risk (history of special education or repeating a grade).

Medical record abstraction Comorbid current and past conditions were rated according to potential impact on current cognition as none, mild (e.g., headache, adjustment disorder), moderate (e.g., chronic migraines, major depressive disorder), or severe (e.g., seizure disorder, skull fracture), following published guidelines (Antinori et al. 2007). CD4 and plasma VL values within 4 weeks preceding the visit, CDC classification (1992), and date of first positive HIV test were abstracted.

Table 1 Neurocognitive domains and assessment instruments

\begin{tabular}{|c|c|c|}
\hline Domain of functioning & Test Name & Measure used in analyses \\
\hline \multicolumn{3}{|c|}{ Monitoring battery (entry, wks $24,48,96$, exit) } \\
\hline \multirow[t]{2}{*}{ Attention/working memory scale } & Digit Span (WAIS-III; Psychological Corporation 1997) & Subtest standard score converted to z-score \\
\hline & Letter-Number Sequencing (WAIS-III) & Subtest standard score converted to z-score \\
\hline \multirow[t]{3}{*}{ Motor/psychomotor scale } & Digit Symbol (WAIS-III) & Subtest standard score converted to z-score \\
\hline & Grooved Pegboard (Strauss et al. 2006) & Dominant hand total time z-score \\
\hline & Timed Gait (Robertson et al. 2006) & Z-score for average time across 3 trials \\
\hline \multirow[t]{3}{*}{ Complex executive scale } & $\begin{array}{l}\text { Trailmaking Test (Part B; Reitan and Wolfson 1993; } \\
\text { Mitrushina et al. 2005) }\end{array}$ & Total completion time z-score \\
\hline & Controlled Oral Word Association (Strauss et al. 2006) & F, A, S \& Animals total correct z-score \\
\hline & $\begin{array}{l}\text { Stroop Test (Interference trial; Norman et al. 2011; } \\
\quad \text { Golden and Freshwater 2002) }\end{array}$ & Interference trial z-score \\
\hline \multirow[t]{4}{*}{ Emotional/behavioral covariates } & Beck Depression Inventory-II (Beck et al. 1987) & Total score \\
\hline & Brief Symptom Inventory (Derogatis 1993) & Global Severity Index \\
\hline & $\begin{array}{l}\text { Alcohol, Smoking and Substance Involvement } \\
\text { Screening Test (World Health Organization 2002) }\end{array}$ & $\begin{array}{l}\text { Risk index for alcohol, marijuana, and } \\
\text { other drugs }\end{array}$ \\
\hline & Adherence & 7-day self-report of percent doses taken \\
\hline \multicolumn{3}{|l|}{ Entry and Exit only } \\
\hline Global functioning & WAIS-III 5-subtest IQ estimate & $\begin{array}{l}\text { Pro-rated IQ estimate derived from } \\
\text { Vocabulary, Similarities, Block Design, } \\
\text { Arithmetic, Matrix Reasoning subtest } \\
\text { Scaled Scores }\end{array}$ \\
\hline \multirow[t]{2}{*}{ Learning and Memory } & $\begin{array}{l}\text { Hopkins Verbal Learning Test-R (Norman et al. 2011; } \\
\text { Benedict et al. 1998) }\end{array}$ & Recognition and Recall corrected T- Scores \\
\hline & $\begin{array}{l}\text { Brief Visuospatial Memory Test-R (Norman et al. 2011; } \\
\text { Benedict et al. 1996) }\end{array}$ & Recognition and Recall corrected T- Scores \\
\hline
\end{tabular}

WAIS-III Wechsler Adult Intelligenc Scale-Third Edition 
Treatment variables included concomitant medications, ART initiation, ART regimen, and, for group 1, de-intensification at ATN061 52-week time point following 24 weeks of sustained viral suppression.

\section{Statistical methods}

\section{Descriptive statistics}

Treatment groups were compared using chi-square tests and $t$ tests.

\section{Modeling}

Hierarchical linear modeling (HLM) using software HLM v7.0 (Raudenbush et al. 2011) was used to analyze the longitudinal neurocognitive scales. All scales (attention, motor, and complex executive) are expressed in $z$-score units with mean= 0 . HLM accounts for the dependency in observations when data have a nested, multilevel structure, such as observations repeated at different times for the same study participant. The model also incorporates person-level covariates such as demographic characteristics or baseline clinical values. Included person-level baseline characteristics were group, gender, age, race/ethnicity, language spoken, education risk (special education class or repeated grade), education level, income earned in the past 30 days, CD4 count, time since HIV diagnosis, and viral load. Time-varying covariates included comorbid diagnosis rating; Beck Depression Inventory-2 (Beck et al. 1987) score; Brief Symptom Inventory (Derogatis 1993) score; medications with psychotropic effects; use of alcohol, cannabis, tobacco, or other drugs; and medication adherence (7-day selfreport of missed doses). Finally, the model also included terms for status of anti-retroviral treatment (including early ART initiation) and ART de-intensification.

Growth curve modeling investigated whether there was nonlinear change in attention, motor, or complex executive indices over time. Both linear and quadratic time measures were included in the model (weeks and weeks ${ }^{2}$, respectively). Because of limits on the number of parameters that could be estimated with five time points and number of random effects, the linear and quadratic terms for time were estimated over all participants rather than for each individual. The growth curve models allowed for testing of group effects, demographic characteristics, and clinical covariates both as factors affecting overall neurocognitive performance and as interactions affecting changes over time in neurocognitive performance. Robust standard errors were used to account for non-normality (Liang and Zeger 1986). Follow-up analyses examined the effect of including baseline IQ in models to account for cognitive reserve; excluding individuals with severe comorbidities from models; and modeling treatment effects after grouping participants according to ART impact into those who never initiated
ART $(n=36)$, those who initiated ART with consistent viral suppression across all subsequent time points $(n=56)$, and those who initiated ART with inconsistent or no viral suppres$\operatorname{sion}(n=83)$.

\section{Results}

\section{Population characteristics}

Among 182 study participants enrolled between April 2008 and July 2010, baseline data were available for 181 participants. Participation dropped from 181 at baseline to 171,151 , 139, and 137 at weeks 24, 48, 96, and 144, respectively. Attrition was significantly higher in group $2(p<0.005)$; the most frequent reason was pregnancy, and participants who discontinued were significantly more likely than those who did not to be female $(p=0.006)$. Some individual test data were eliminated from analyses due to issues with validity (e.g., long fingernails interfering with fine motor performance).

Table 2 shows demographic characteristics of study participants at baseline. Mean age was 21.0 years. Participants were predominantly male (80.7\%), non-Hispanic Black/AfricanAmerican (65.2\%) or Hispanic (22.7\%), self-identified as gay or bisexual (71.2\%), and high school educated or beyond $(72.3 \%)$, with $40.8 \%$ currently in school and less than half (42.6\%) employed. Approximately $21.5 \%$ reported having repeated a grade, and $22.7 \%$ had received some form of special education. Nine participants $(5 \%)$ reported using a language other than English at home. Of those, one Spanishspeaking participant was tested in Spanish; the remainder, who were bilingual, completed testing in English. Demographic differences between groups are presented in Table 2.

\section{Clinical HIV characteristics}

According to reported dates for first positive HIV test, approximately half the sample had been diagnosed with HIV for less than a year (Table 3; see Agwu et al. 2012 for discussion of length of infection in associated ATN 061). Significantly fewer participants in group $2(7.6 \%)$ had been diagnosed less than 4 months prior to baseline compared with group $1(25.0 \%)$ or group $3(35.6 \%)(p=0.0024)$. Youth with CD4 counts $>350$ at baseline accounted for $94.6 \%$ of group 1, $98.5 \%$ of group 2, and $6.8 \%$ of group 3 ; inclusion of participants in groups 1 and 2 with CD4 count $<350$ was due to changes in CD4 between eligibility screening and baseline assessments. Almost $90 \%$ overall were in CDC category A, and all but $1.7 \%$ had VL above 400 copies at baseline; $10.2 \%$ of group 3 had AIDS by CD4 count $<200$ at baseline. Baseline VL distribution differed across the three groups, with $10.7 \%$ of group 1 participants having VL above 100,000 copies vs. $3.0 \%$ for group 2 and 
Table 2 Demographic and baseline data

\begin{tabular}{|c|c|c|c|c|c|c|c|c|c|}
\hline \multirow[t]{2}{*}{ Characteristic } & \multicolumn{2}{|c|}{$\begin{array}{l}\text { Group } 1 \text { initiating ART } \\
\text { with CD4+>350 }\end{array}$} & \multicolumn{2}{|c|}{$\begin{array}{l}\text { Group 2, CD4+>350, } \\
\text { not initiating ART }\end{array}$} & \multicolumn{2}{|c|}{$\begin{array}{l}\text { Group } 3 \text { initiating ART } \\
\text { with CD4+<350 }\end{array}$} & \multicolumn{2}{|l|}{ Overall } & \multirow[t]{2}{*}{$p$ value } \\
\hline & $\begin{array}{l}\text { Count/ } \\
\text { mean }\end{array}$ & $\begin{array}{l}\text { Percent/std. } \\
\text { dev. }\end{array}$ & $\begin{array}{l}\text { Count/ } \\
\text { mean }\end{array}$ & $\begin{array}{l}\text { Percent/std. } \\
\text { dev. }\end{array}$ & $\begin{array}{l}\text { Count/ } \\
\text { mean }\end{array}$ & $\begin{array}{l}\text { Percent/std. } \\
\text { dev. }\end{array}$ & $\begin{array}{l}\text { Count/ } \\
\text { mean }\end{array}$ & $\begin{array}{l}\text { Percent/std. } \\
\text { dev. }\end{array}$ & \\
\hline \multicolumn{10}{|l|}{ Time point } \\
\hline Baseline & 56 & 100.0 & 66 & 100.0 & 59 & 100.0 & 181 & 100.0 & 0.0020 \\
\hline Week 24 & 52 & 92.9 & 63 & 95.5 & 56 & 94.9 & 171 & 94.5 & \\
\hline Week 48 & 48 & 85.7 & 53 & 80.3 & 50 & 84.7 & 151 & 83.4 & \\
\hline Week 96 & 48 & 85.7 & 45 & 68.2 & 46 & 78.0 & 139 & 76.8 & \\
\hline Week 144 & 47 & 83.9 & 44 & 66.7 & 46 & 78.0 & 137 & 75.7 & \\
\hline Age (years) & 20.9 & 1.6 & 21.2 & 1.8 & 20.8 & 1.9 & 21.0 & 1.8 & 0.5104 \\
\hline Male gender & 49 & 87.5 & 45 & 68.2 & 52 & 88.1 & 146 & 80.7 & 0.0051 \\
\hline Race/ethnicity & & & & & & & & & 0.7933 \\
\hline Hispanic & 11 & 19.6 & 18 & 27.3 & 12 & 20.3 & 41 & 22.7 & \\
\hline Non-Hispanic White & 4 & 7.1 & 6 & 9.1 & 3 & 5.1 & 13 & 7.2 & \\
\hline Non-Hispanic Black/African American & 38 & 67.9 & 38 & 57.6 & 42 & 71.2 & 118 & 65.2 & \\
\hline Asian/Pacific Islander & 2 & 3.6 & 2 & 3.0 & 0 & 0.0 & 4 & 2.2 & \\
\hline Other or mixed race & 1 & 1.8 & 2 & 3.0 & 2 & 3.4 & 5 & 2.8 & \\
\hline Language at home & & & & & & & & & 0.4694 \\
\hline English & 51 & 91.1 & 65 & 98.5 & 56 & 94.9 & 172 & 95.0 & \\
\hline Spanish & 4 & 7.1 & 1 & 1.5 & 2 & 3.4 & 7 & 3.9 & \\
\hline Other & 1 & 1.8 & 0 & 0.0 & 1 & 1.7 & 2 & 1.1 & \\
\hline Transgender & 2 & 3.6 & 3 & 4.5 & 4 & 6.8 & 9 & 5.0 & 0.7661 \\
\hline Sexual orientation & & & & & & & & & 0.0233 \\
\hline Straight (heterosexual) & 10 & 17.9 & 25 & 37.9 & 11 & 18.6 & 46 & 25.4 & \\
\hline Gay/lesbian (homosexual) & 41 & 73.2 & 31 & 47.0 & 39 & 66.1 & 111 & 61.3 & \\
\hline Bisexual & 3 & 5.4 & 9 & 13.6 & 6 & 10.2 & 18 & 9.9 & \\
\hline Not sure/questioning & 2 & 3.6 & 0 & 0.0 & 1 & 1.7 & 3 & 1.7 & \\
\hline Refused to answer & 0 & 0.0 & 1 & 1.5 & 2 & 3.4 & 3 & 1.7 & \\
\hline Educational status & & & & & & & & & 0.6315 \\
\hline Attending school & 19 & 33.9 & 19 & 28.8 & 20 & 33.9 & 58 & 32.0 & \\
\hline GED program & 5 & 8.9 & 4 & 6.1 & 7 & 11.9 & 16 & 8.8 & \\
\hline Not currently in school & 30 & 53.6 & 42 & 63.6 & 32 & 54.2 & 104 & 57.5 & \\
\hline Other & 2 & 3.6 & 1 & 1.5 & 0 & 0.0 & 3 & 1.7 & \\
\hline Level of education & & & & & & & & & 0.8382 \\
\hline Eighth grade or less & 2 & 3.6 & 1 & 1.5 & 2 & 3.4 & 5 & 2.8 & \\
\hline Not completed high school & 16 & 28.6 & 17 & 25.8 & 12 & 20.3 & 45 & 24.9 & \\
\hline High school graduate & 13 & 23.2 & 17 & 25.8 & 21 & 35.6 & 51 & 28.2 & \\
\hline Some education after high school & 23 & 41.1 & 26 & 39.4 & 21 & 35.6 & 70 & 38.7 & \\
\hline College graduate & 2 & 3.6 & 5 & 7.6 & 3 & 5.1 & 10 & 5.5 & \\
\hline Repeated a grade & 14 & 25.0 & 10 & 15.2 & 15 & 25.4 & 39 & 21.5 & 0.3041 \\
\hline Special class or education & 18 & 32.1 & 8 & 12.1 & 15 & 25.4 & 41 & 22.7 & 0.0283 \\
\hline Current employment & & & & & & & & & 0.0098 \\
\hline Full-time & 14 & 25.0 & 22 & 33.3 & 7 & 11.9 & 43 & 23.8 & \\
\hline Part-time & 5 & 8.9 & 13 & 19.7 & 16 & 27.1 & 34 & 18.8 & \\
\hline Not employed & 36 & 64.3 & 31 & 47.0 & 36 & 61.0 & 103 & 56.9 & \\
\hline Refused to answer & 1 & 1.8 & 0 & 0.0 & 0 & 0.0 & 1 & 0.6 & \\
\hline Past year income & & & & & & & & & 0.4411 \\
\hline$<\$ 6000$ & 39 & 69.6 & 38 & 57.6 & 44 & 74.6 & 121 & 66.9 & \\
\hline$\$ 6000-\$ 35,999$ & 15 & 26.8 & 25 & 37.9 & 15 & 25.4 & 55 & 30.4 & \\
\hline
\end{tabular}


Table 2 (continued)

\begin{tabular}{|c|c|c|c|c|c|c|c|c|c|}
\hline \multirow[t]{2}{*}{ Characteristic } & \multicolumn{2}{|c|}{$\begin{array}{l}\text { Group } 1 \text { initiating ART } \\
\text { with } \mathrm{CD} 4+>350\end{array}$} & \multicolumn{2}{|c|}{$\begin{array}{l}\text { Group 2, CD4+>350, } \\
\text { not initiating ART }\end{array}$} & \multicolumn{2}{|c|}{$\begin{array}{l}\text { Group } 3 \text { initiating ART } \\
\text { with CD4+<350 }\end{array}$} & \multicolumn{2}{|l|}{ Overall } & \multirow[t]{2}{*}{$p$ value } \\
\hline & $\begin{array}{l}\text { Count/ } \\
\text { mean }\end{array}$ & $\begin{array}{l}\text { Percent/std. } \\
\text { dev. }\end{array}$ & $\begin{array}{l}\text { Count/ } \\
\text { mean }\end{array}$ & $\begin{array}{l}\text { Percent/std. } \\
\text { dev. }\end{array}$ & $\begin{array}{l}\text { Count/ } \\
\text { mean }\end{array}$ & $\begin{array}{l}\text { Percent/std. } \\
\text { dev. }\end{array}$ & $\begin{array}{l}\text { Count/ } \\
\text { mean }\end{array}$ & $\begin{array}{l}\text { Percent/std. } \\
\text { dev. }\end{array}$ & \\
\hline Refused to answer & 1 & 1.8 & 1 & 1.5 & 0 & 0.0 & 2 & 1.1 & \\
\hline Unknown & 1 & 1.8 & 2 & 3.0 & 0 & 0.0 & 3 & 1.7 & \\
\hline \multicolumn{10}{|c|}{ Potential impact of comorbid diagnoses } \\
\hline Severe & 3 & 5.4 & 4 & 6.1 & 3 & 5.1 & 10 & 5.5 & \multirow[t]{4}{*}{0.9894} \\
\hline Moderate & 17 & 30.4 & 24 & 36.4 & 20 & 33.9 & 59 & 33.7 & \\
\hline Mild & 5 & 8.9 & 7 & 10.6 & 6 & 10.2 & 16 & 10.0 & \\
\hline None & 31 & 55.3 & 31 & 46.9 & 30 & 50.8 & 89 & 50.8 & \\
\hline
\end{tabular}

$17.6 \%$ for group $3(p<0.005)$. ARV regimens were provider selected except for group 1, who initiated atazanavir/ritonavir plus tenofovir/emtricitabine as part of ATN 061. Regimens prescribed for group 3, as well as the subset of group 2 who subsequently initiated treatment per guidelines, were standard combinations of protease inhibitors (PI), nucleoside reverse transcriptase inhibitors (NRTI), non-nucleoside reverse transcriptase inhibitors (NNRTI), and integrase inhibitors (II). Altogether, 104 study participants used PI-based regimens during most or all of study duration, 34 were on NNRTIs, 2 were on II regimens, and 1 each were on NNRTI/II and PI/II regimens. Thirty-three participants used regimens containing efavirenz for most or all of study duration; an additional four used an efavirenz-containing regimen for part of their time on study. Reported adherence averaged 85 to $90 \%$ over the course of the study (data not shown). There was a pronounced effect of treatment on both VL and CD4 counts, with VL decreasing and CD4 counts increasing between entry and week 144 for youth who initiated treatment (Table 3). Of group 1 participants, 35 underwent treatment de-intensification at week 48 to atazanavir/ritonavir monotherapy.

\section{Neurocognitive measures over time by group}

Figure 1a-c shows descriptive statistics by group for the three neurocognitive scales over time.

\section{Hierarchical linear modeling}

Table 4 shows the results of fitting hierarchical linear models to the attention, motor, and complex executive scales. All models contain terms for demographic and clinical covariates, as well as for change over time.

Attention index The attention index, adjusted for covariates, increased from 0.161 at baseline to 0.317 at week 96 , and then decreased slightly to 0.263 by week 144 . Significantly lower attention index at baseline was seen in youth who were Hispanic, had education risk, or had comorbid diagnoses with potentially severe neurocognitive impact (e.g., seizure disorder). Other covariates (see "Methods" section) were not significantly associated with the attention scale. Covariates did not interact significantly with the attention index over time.

Motor index The motor index increased from -1.045 at baseline to -0.421 at week 96 and then decreased slightly to -0.553 by week 144 . Male youth had significantly better motor performance than females. Youth with comorbid diagnoses with potentially severe or moderate neurocognitive impact had significantly lower mean baseline motor index than those with mild or no diagnoses. Other covariates were not significantly associated with the motor scale.

Complex executive index The complex executive index increased from 0.179 at baseline to 0.311 at week 96 and then decreased to 0.209 by week 144 . Baseline executive index was significantly lower for participants who were older, Hispanic and non-Hispanic Black (vs. non-Hispanic White/other), had education risk, or had severe potential impact of diagnoses. Other covariates were not significantly associated with the complex executive scale.

Notably, there were no significant differences between study groups at baseline or in changes over time in the attention index, motor index, or executive index. Similarly, there were no observed differences in any index for participants who de-intensified their ARV medication. Relationships between covariates and index scores differed by comorbid diagnosis impact but did not interact with treatment (Table 4). Follow-up analyses showed that including baseline IQ as a covariate, excluding individuals with severe comorbidities, or grouping participants according to virologic response to ART did not cause a significant treatment effect on index scores to 
Table 3 Clinical data at baseline and end of study

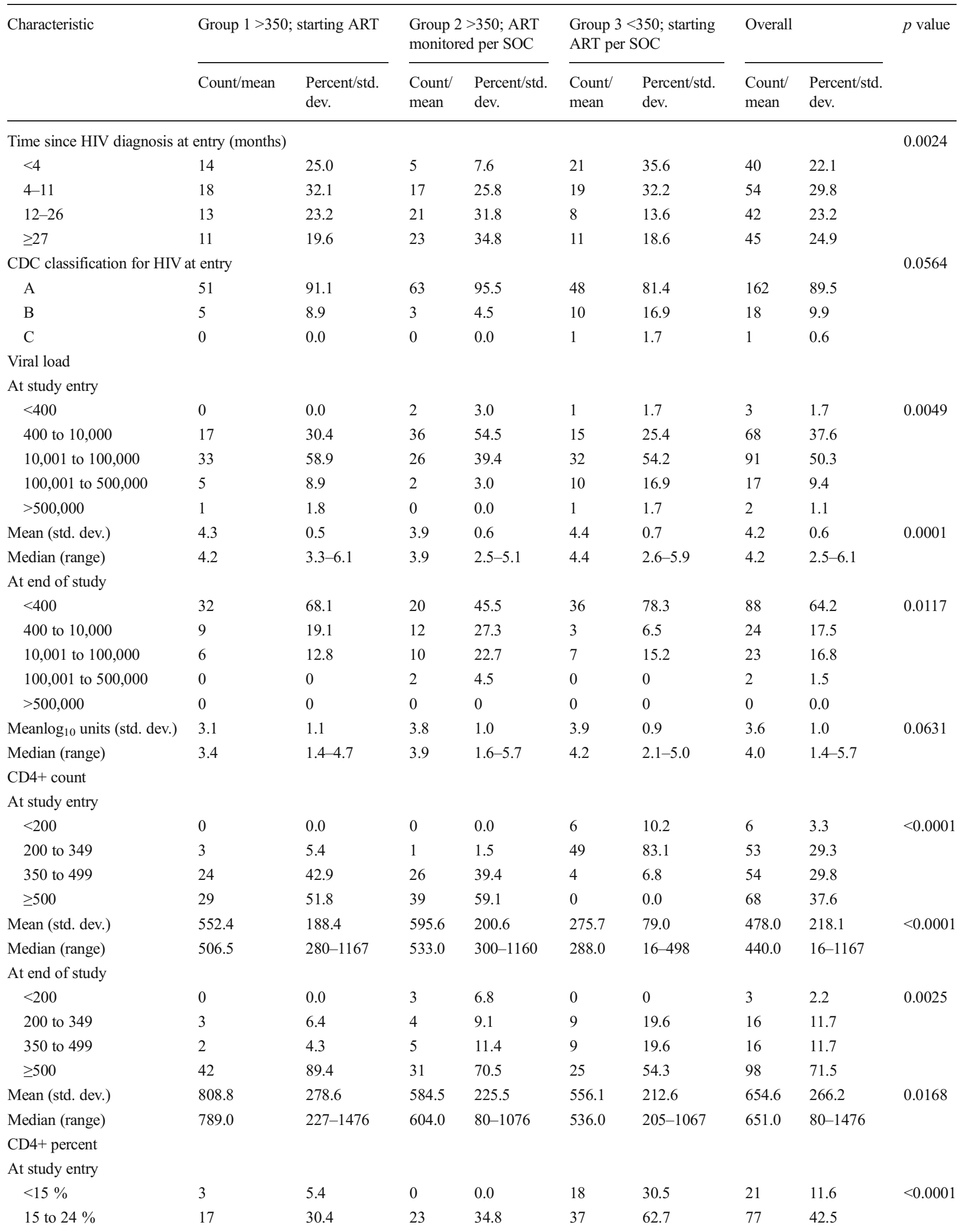


Table 3 (continued)

\begin{tabular}{|c|c|c|c|c|c|c|c|c|c|}
\hline \multirow[t]{2}{*}{ Characteristic } & \multicolumn{2}{|c|}{ Group $1>350$; starting ART } & \multicolumn{2}{|c|}{$\begin{array}{l}\text { Group } 2>350 \text {; ART } \\
\text { monitored per SOC }\end{array}$} & \multicolumn{2}{|c|}{$\begin{array}{l}\text { Group } 3<350 \text {; starting } \\
\text { ART per SOC }\end{array}$} & \multicolumn{2}{|l|}{ Overall } & \multirow[t]{2}{*}{$p$ value } \\
\hline & Count/mean & $\begin{array}{l}\text { Percent/std. } \\
\text { dev. }\end{array}$ & $\begin{array}{l}\text { Count/ } \\
\text { mean }\end{array}$ & $\begin{array}{l}\text { Percent/std. } \\
\text { dev. }\end{array}$ & $\begin{array}{l}\text { Count/ } \\
\text { mean }\end{array}$ & $\begin{array}{l}\text { Percent/std. } \\
\text { dev. }\end{array}$ & $\begin{array}{l}\text { Count/ } \\
\text { mean }\end{array}$ & $\begin{array}{l}\text { Percent/std. } \\
\text { dev. }\end{array}$ & \\
\hline$>24 \%$ & 36 & 64.3 & 43 & 65.2 & 4 & 6.8 & 83 & 45.9 & \\
\hline Mean (std. dev.) & 27.2 & 7.1 & 28.3 & 8.2 & 17.5 & 6.2 & 23.8 & 8.7 & $<0.0001$ \\
\hline Median (range) & 28.4 & $13-40$ & 28.1 & $15-50$ & 18.0 & $1-34$ & 23.8 & $1-50$ & \\
\hline \multicolumn{10}{|l|}{ At end of study } \\
\hline$<15 \%$ & 4 & 8.5 & 5 & 11.4 & 2 & 4.3 & 11 & 8.0 & 0.4513 \\
\hline 15 to $24 \%$ & 2 & 4.3 & 4 & 9.1 & 6 & 13 & 12 & 8.8 & \\
\hline$>24 \%$ & 41 & 87.2 & 34 & 77.3 & 35 & 76.1 & 110 & 80.3 & \\
\hline Mean (std. dev.) & 35.5 & 10.3 & 30.7 & 11.4 & 31.4 & 9.0 & 32.6 & 10.4 & 0.0168 \\
\hline Median (range) & 38.0 & $10-53$ & 32.0 & $0.3-52$ & 31.0 & $7.5-50$ & 34.0 & $0.3-53.0$ & \\
\hline
\end{tabular}

emerge. Higher full-scale IQ at baseline was associated with higher index scores at baseline and greater improvement in motor/psychomotor index scores over time, but the inclusion of IQ in models of group effects did not alter treatment findings.

\section{Discussion}

This paper reports findings from the first prospective observational study of neurocognitive functioning in YLWH initiating ART at different CD4 thresholds. Models of trajectories of neurocognitive functioning over 3 years were examined for both positive and negative change. A broad neurocognitive, behavioral, demographic, and health history database allowed for the evaluation of several cognitive domains and multiple potential confounding factors. The key finding is that all three cognitive functional domains considered here improved significantly over time, each peaking at about 96 weeks into the study. Some degree of positive change was anticipated due to the likelihood of practice effects for neurocognitive measures (Duff 2012; Woods et al. 2006); our analytic approach was designed to compare the magnitude of change across groups. However, while there were modifying effects of demographic characteristics and non-HIV medical diagnoses, the magnitude and direction of change were not associated with treatment group or with clinical indicators of HIV-related disease factors. In addition, there were no differences associated with treatment de-intensification following viral suppression among earlytreated youth, supporting safety of this management approach.

Prior studies with adults have found that ART is associated with modest improvements in cognitive functioning overall and that these improvements are seen largely in the areas of attentional, motor, and executive functioning (Al-Khindi et al. 2011). The sensitivity of these functional domains to HIV as well as to ART was the reason they were chosen for longitudinal monitoring in youth in the study reported here. The measures selected were ones that had a well-established track record in the adult HIV literature. The significant associations of the neurocognitive measures with other risk factors for the participants, such as educational risk and comorbid diagnoses, were in the predicted directions, suggesting that the lack of significant treatment effects was not likely due to insensitivity of the measures. Further support for measurement sensitivity comes from baseline findings showing subtle associations of some cognitive variables with CD4 count (Nichols et al. 2013). Nevertheless, treatment effects were not detected for our groups of youth with behaviorally acquired HIV.

There are several possible reasons that we did not observe effects of ART on cognitive functioning. One possibility is that, despite concern raised by the baseline findings regarding HIV impact on the CNS even in our relatively healthy cohort of youth, the contribution of HIV to neurocognitive functioning in our complex cohort is small enough relative to other influences and comorbidities that improvements with ART were too subtle to be detected with our sample size. A second possible explanation is that the medications did not adequately penetrate the central nervous system; a relatively narrow range of penetrance was represented and regimens for the most part were not highly penetrant (data not shown). A third possibility that could be raised is that participants were not adhering to their medications; however, reported adherence was reasonably good overall, supported by changes in CD4 and viral load, adherence was included as a covariate in analyses, and analyzing data according to virologic ART response did not alter the findings. Fourth, it may be that the observed impairments are related to persistent immune activation and inflammation established early in infection that is not reversed by ART (Ancuta et al. 2008; Wallet et al. 2010). Data collected 
Table 4 Hierarchical linear model for attention, motor and complex executive scales

\begin{tabular}{|c|c|c|c|}
\hline HLM terms & Coefficient & Std. error & $p$ value \\
\hline \multicolumn{4}{|l|}{ Attention scale } \\
\hline \multicolumn{4}{|l|}{ Model for baseline intercept } \\
\hline Intercept & 0.161 & 0.175 & 0.358 \\
\hline Hispanic (vs. non-Hispanic white and other) & -0.412 & 0.193 & 0.034 \\
\hline Non-Hispanic Black (vs. non-Hispanic white and other) & -0.349 & 0.178 & 0.052 \\
\hline Education risk (special class or repeated grade) & -0.427 & 0.106 & $<.001$ \\
\hline \multicolumn{4}{|l|}{ Model for change over time } \\
\hline Linear term & 0.083 & 0.023 & $<.001$ \\
\hline Quadratic term & -0.011 & 0.004 & 0.005 \\
\hline \multicolumn{4}{|l|}{ Effect of diagnoses with severe potential impact } \\
\hline Intercept & -0.234 & 0.119 & 0.051 \\
\hline Baseline viral load & 0.543 & 0.144 & $<.001$ \\
\hline \multicolumn{4}{|l|}{ Effect of diagnoses with moderate potential impact } \\
\hline Intercept & 0.097 & 0.053 & 0.072 \\
\hline Baseline viral load & 0.080 & 0.049 & 0.102 \\
\hline \multicolumn{4}{|l|}{ Motor Scale } \\
\hline \multicolumn{4}{|l|}{ Model for baseline intercept } \\
\hline Intercept & -1.045 & 0.153 & $<.001$ \\
\hline Male gender & 0.481 & 0.168 & 0.005 \\
\hline \multicolumn{4}{|l|}{ Model for change over time } \\
\hline Linear term & 0.304 & 0.027 & $<.001$ \\
\hline Quadratic term & -0.037 & 0.004 & $<.001$ \\
\hline \multicolumn{4}{|l|}{ Effect of diagnoses with severe potential impact } \\
\hline Intercept & -1.670 & 0.195 & $<.001$ \\
\hline Male gender & 1.257 & 0.243 & $<.001$ \\
\hline \multicolumn{4}{|l|}{ Effect of diagnoses with moderate potential impact } \\
\hline Intercept & -0.474 & 0.244 & 0.053 \\
\hline Male gender & 0.440 & 0.259 & 0.092 \\
\hline \multicolumn{4}{|l|}{ Complex executive scale } \\
\hline \multicolumn{4}{|l|}{ Model for baseline intercept } \\
\hline Intercept & 0.179 & 0.127 & 0.161 \\
\hline Age & -0.081 & 0.033 & 0.016 \\
\hline Hispanic (vs. non-Hispanic White and other) & -0.575 & 0.138 & $<.001$ \\
\hline Non-Hispanic Black (vs. non-Hispanic White and other) & -0.472 & 0.126 & $<.001$ \\
\hline Education risk (special class or repeated grade) & -0.349 & 0.096 & $<.001$ \\
\hline \multicolumn{4}{|l|}{ Model for change over time } \\
\hline Linear term & 0.089 & 0.025 & $<.001$ \\
\hline Quadratic term & -0.014 & 0.004 & 0.001 \\
\hline \multicolumn{4}{|l|}{ Effect of diagnoses with severe potential impact } \\
\hline Intercept & -1.640 & 0.119 & $<.001$ \\
\hline Age & 0.074 & 0.039 & 0.061 \\
\hline Male gender & 1.529 & 0.121 & $<.001$ \\
\hline CD4 at baseline & 0.154 & 0.021 & $<.001$ \\
\hline Viral load at baseline & 0.702 & 0.068 & $<.001$ \\
\hline \multicolumn{4}{|l|}{ Effect of diagnoses with moderate potential impact } \\
\hline Intercept & -0.227 & 0.148 & 0.127 \\
\hline Age & -0.135 & 0.035 & $<.001$ \\
\hline
\end{tabular}


Table 4 (continued)

\begin{tabular}{|c|c|c|c|}
\hline HLM terms & Coefficient & Std. error & $p$ value \\
\hline Male gender & 0.377 & 0.160 & 0.020 \\
\hline CD4 at baseline & 0.033 & 0.024 & 0.177 \\
\hline Viral load at baseline & -0.014 & 0.066 & 0.835 \\
\hline
\end{tabular}

from ATN 061 have demonstrated that T cell activation decreases with treatment but does not approach that of uninfected adolescents. In addition, ATN 061 demonstrated that, even with early initiation of ART, inflammatory markers including sCD14, sCD163, and sCD27 began and remained significantly higher than among a cohort of uninfected comparison youth similar in age, race, and substance use to the ATN 061 cohort (Rudy et al. 2014). An additional possibility is that the impairments seen at baseline were not related to HIV and that the CD4 findings were spurious. Rigorous measures were taken to account for other influences on neurocognitive functioning (Nichols et al. 2013), and exclusion of individuals with the most severe comorbidities did not affect the findings, but it should be acknowledged that controversy exists regarding the specificity of mild, asymptomatic neurocognitive impairments in adults with HIV disease (Gisslen et al. 2011; Grant et al. 2014; McDonnell et al. 2014). Further studies are needed to explore the impact of ART in the context of treatment begun in acute infection, using additional CNS measures such as neuroimaging, to evaluate regimens with a wider range of $\mathrm{CNS}$ penetrance, and to examine longitudinal associations with biomarkers of immune activation and inflammation.

With changes in US treatment guidelines, which now recommend ART in all HIV-infected persons regardless of immune function, evaluation of potential neurotoxicity of regimens has assumed greater importance. Particularly for young, asymptomatic individuals facing a lifetime of ART, concern about potential negative impacts of ART on functioning may decrease willingness to initiate or adhere to treatment. It is noteworthy that our findings indicated similar neurocognitive improvement in participants regardless of ART, suggesting lack of a negative impact of ART in general. Exploratory analyses including efavirenz, a medication that has been associated with CNS toxicity (Ciccarelli et al. 2011; Decloedt and Maartens 2013), did not find a differential effect on neurocognitive functioning. However, the number of youth taking this medication was small. Further studies are needed to support the safety of early ART in youth.

As noted in our description of baseline findings from ATN 071 (Nichols et al. 2013), a high percentage of youth in our cohort demonstrated neurocognitive impairment. Important questions remain for future studies, particularly if further studies continue to show that these impairments do not improve with ART. The origin of impairments may include modifiable factors such as substance use that could be the target of preventive interventions. Potential interventions could also include cognitive remediation, lifestyle modification such as exercise, as well as provision of enhanced education for healthcare-related and other daily living tasks for youth with impairment(s). Youth with the most significant impairments may be at risk for poor adherence, potentially leading to cognitive decline as part of disease progression (Ettenhofer et al. 2010); cognitive screening could be used to select youth for more intensive adherence support. The potential impact of impairments on other HIV prevention efforts, such as effectiveness of risk behavior reduction interventions, has public health implications and merits further research. Finally, longterm studies are needed to determine whether YLWH who have cognitive impairments are more vulnerable to cognitive decline associated with other risks such as head injury or aging. Exploratory analyses of our data demonstrated that neurocognitive impairment at baseline was associated with differences in trajectory of change, a finding that will be explored further in subsequent publications; however, it should be noted that inclusion of baseline cognitive performance or HAND diagnosis did not alter the finding of no treatment effects.

This study has several limitations. A primary limitation is that, while a portion of the participants with CD4 $>350$ were randomized to treatment or no treatment, the study as a whole was not a randomized clinical trial. In fact, treatment guidelines to initiate ART following HIV diagnosis preclude randomized studies comparing treated and untreated YLWH. Differences between the three study groups in some characteristics other than CD4 at baseline may have contributed to lack of a treatment effect and limit conclusions that can be drawn. However, it should be noted that analyses considered these characteristics as well as other variables. An additional limitation was the lack of an uninfected control group which could address nonspecific effects such as practice and possible developmental changes over time (however, age-standardized scores were used to account for development). Future studies should follow a well-matched uninfected group of youth to help account for these effects. Measurement of nonspecific clinical effects of participation, such as more frequent interaction with the clinic team, may also partially explain the non-ARTrelated positive change. Measures of memory and learning were included only at baseline and week 144 and 
Fig. 1 Descriptive statistics by group for $\mathbf{a}$ attention, $\mathbf{b}$ motor, and $\mathbf{c}$ complex executive scales over time
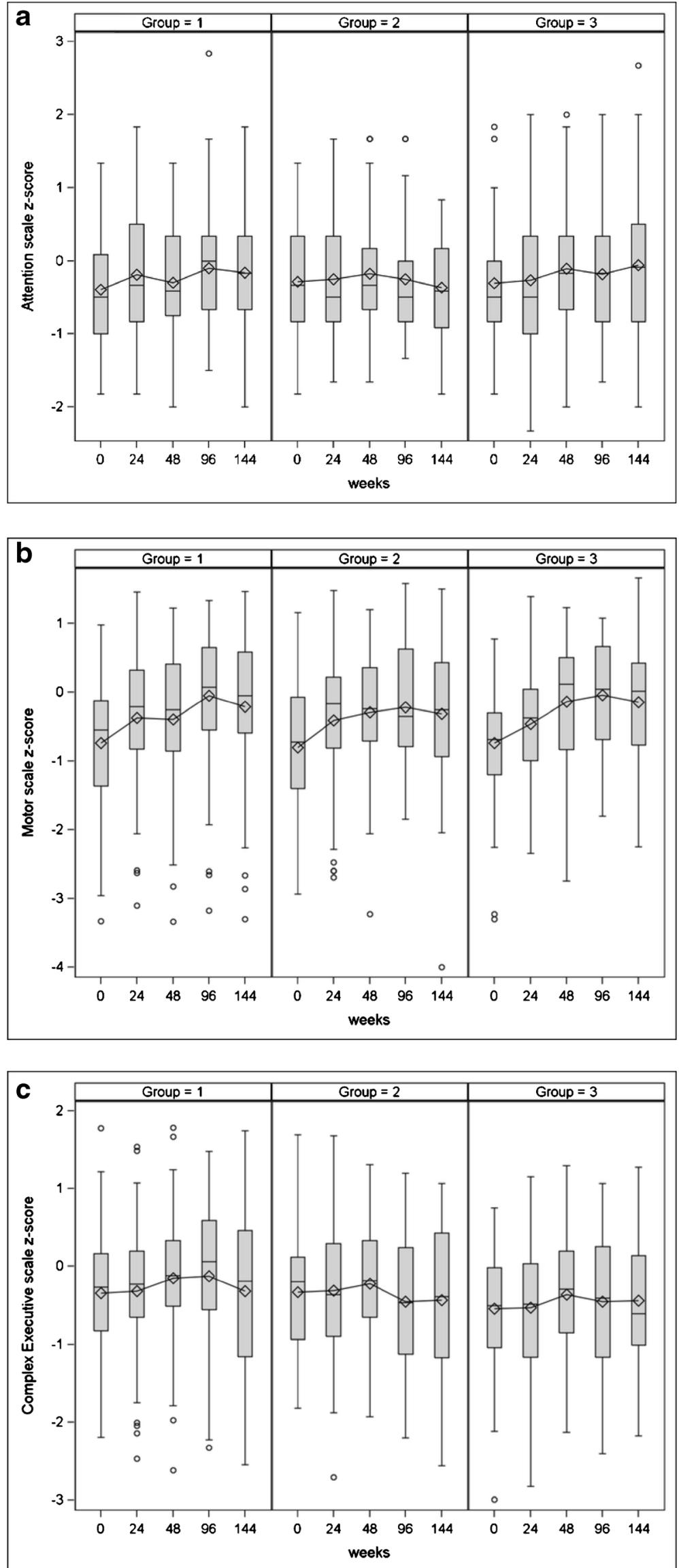
were not included in these analyses; however, exploratory analyses demonstrated no associations of treatment with change in these measures. Although a significant number of youth were recently diagnosed with HIV, the study did not focus on youth with acute infection, a group likely to be most impacted by changes in treatment guidelines. Follow-up continued for 3 years, which may not have been protracted enough to observe longer term impacts of HIV and ART in youth. Finally, sample sizes were small for evaluation of some effects such as treatment de-intensification.

In conclusion, despite evidence of significant impairment at baseline, youth with behaviorally acquired HIV showed modest positive changes in neurocognitive functioning over 3 years of follow-up that were not related to antiretroviral treatment. Further research is needed to evaluate the impact of earlier treatment, newer regimens, and those with greater CNS penetrance.

Acknowledgments This work was supported by The Adolescent Trials Network for HIV/AIDS Interventions (ATN; 5 U01 HD 40533 and 5 U01 HD 40474) from the National Institutes of Health through the National Institute of Child Health and Human Development (B. Kapogiannis, S. Lee, C. Worrell), with supplemental funding from the National Institutes of Drug Abuse (N. Borek, D. Lawrence) and Mental Health (P. Brouwers, S. Allison). The study was scientifically reviewed by the ATN's Behavioral Leadership Group. Network, scientific, and logistical support was provided by the ATN Coordinating Center (C. Wilson, C. Partlow) at the University of Alabama at Birmingham. Network operations and data management support was provided by the ATN Data and Operations Center at Westat, Inc. (J. Korelitz, B. Driver). Please note that listing in the acknowledgments section does not imply endorsement of the findings and conclusions of this manuscript. We acknowledge the contribution of the investigators and staff at the following ATN 071 sites that participated in this study (listed in order of Site Principal Investigator, Study Coordinator, Psychologist): University of South Florida (Patricia Emmanuel, M.D., Priscilla Julian, RN, Tiffany Chenneville, Ph.D.); Children's Hospital of Los Angeles (Marvin Belzer, M.D., Michelle Bradford, B.A., Anita Hamilton, Ph.D., ABPP-CN); Children's National Medical Center (Lawrence D'Angelo, M.D., Connie Trexler, RN, Donna Marschall, Ph.D.); University of Pennsylvania and the Children's Hospital of Philadelphia (Mary Tanney, M.P.H., M.S.N., C.P.N.P., Linda Hawkins, M.S., Ed.D.; Jerilynn Radcliffe, Ph.D.); Stroger Hospital and the CORE Center (Jaime Martinez, M.D., Kelly Bojan, D.N.P., Harold Fuentes, Psy.D.); University Pediatric Hospital (Irma Febo, M.D., Hazel Ayala-Flores, B.S.N., Nydia Scalley-Trifilio, M.A.); Montefiore Medical Center (Donna Futterman, M.D., Elizabeth Bruce, M.D., Erica Weiss, M.A.); Mount Sinai Medical Center, Adolescent Health Center (John Steever, M.D., Mary Geiger, M.P.H., Marijane Lehr, Ph.D.); University of California, San Francisco (Barbara Moscicki, M.D., Lisa Irish, B.S.N., Rita Jeremy, Ph.D.); Tulane Medical Center (Sue Ellen Abdalian, M.D., Leslie Kozina, RN, Patricia Sirois, Ph.D.); University of Maryland (Vicki Tepper, Ph.D., Reshma Gorle, M.P.H., Terry Lee-Wilk, Ph.D.); University of Miami School of Medicine (Lawrence Friedman, M.D., Donna Maturo, M.S.N., Anai Cuadra, Ph.D.); Children's Diagnostic \& Treatment Center (Ana Puga, M.D., Amy Inman, B.S., Doyle Patton, Ph.D.); St Jude Children's Research Hospital (Patricia Flynn, M.D., Mary Dillard, B.S.N., Patricia Garvie, Ph.D., Megan Wilkins, Ph.D.); Lurie Children's Hospital (Robert Garofalo, M.D., M.P.H., Ann Sanders, M.P.H., Andrea Boyd, Ph.D.); University of Southern California (Andrea Kovacs, M.D., Michelle Aranda, M.P.H., Maribel Mejia, Ph.D.); Children's Hospital of
Michigan (Ellen Moore, M.D., Ayanna Walters, RN, Salome Cockern, Ph.D.); Children's Hospital of Denver (Elizabeth McFarland, M.D., Kerry Hahn, B.S., CCRP, Robin McEvoy, Ph.D.); Howard University (Sohail Rana, M.D., Meseret Deressa, M.P.H., Eshauna Padilla, M.A.); and Johns Hopkins University (Allison George Agwu, M.D., Todd Noletto, M.P.H., Laura Margolis, Ph.D.). We sincerely thank Pim Brouwers, Ph.D., for his contributions to the study and this manuscript, the ATN Community Advisory Board, and the youth who participated in the study.

Dr. Garvie's role on the project was initiated while on faculty at St. Jude Children's Research Hospital. Dr. Garvie is now at the Children's Diagnostic \& Treatment Center; however, interim participation was as a contracted consultant.

\section{Compliance with Ethical Standards}

The study was approved by Institutional Review Boards at all participating institutions; participants provided written informed consent in accordance with institutional requirements prior to enrollment.

Conflict of interest The authors declare that they have no competing interests.

Source of funding This work was supported by The Adolescent Trials Network for HIV/AIDS Interventions (5 U01 HD 40533 and 5 U01 HD 40474) from the National Institutes of Health through the National Institute of Child Health and Human Development (B. Kapogiannis, C. Worrell), with supplemental funding from the National Institutes of Drug Abuse (N. Borek, D. Lawrence) and Mental Health (P. Brouwers, S. Allison). The comments and views of the authors do not necessarily represent the views of the Eunice Kennedy Shriver National Institute of Child Health and Human Development.

Open Access This article is distributed under the terms of the Creative Commons Attribution 4.0 International License (http:// creativecommons.org/licenses/by/4.0/), which permits unrestricted use, distribution, and reproduction in any medium, provided you give appropriate credit to the original author(s) and the source, provide a link to the Creative Commons license, and indicate if changes were made.

\section{References}

(1992) 1993 Revised classification system for HIV infection and expanded surveillance case definition for AIDS among adolescents and adults. MMWR Recomm Rep 41: 1-19

Agwu AL, Bethel J, Hightow-Weidman LB, Sleasman JW, Wilson CM, Rudy B, Kapogiannis BG (2012) Substantial multiclass transmitted drug resistance and drug-relevant polymorphisms among treatmentnaive behaviorally HIV-infected youth. AIDS Patient Care STDS 26:193-6

Al-Khindi T, Zakzanis KK, van Gorp WG (2011) Does antiretroviral therapy improve HIV-associated cognitive impairment? A quantitative review of the literature. J Int Neuropsychol Soc 17:956-69

Ancuta P, Kamat A, Kunstman KJ, Kim EY, Autissier P, Wurcel A, Zaman T, Stone D, Mefford M, Morgello S, Singer EJ, Wolinsky SM, Gabuzda D (2008) Microbial translocation is associated with increased monocyte activation and dementia in AIDS patients. PLoS One 3:e2516

Antinori A, Arendt G, Becker JT, Brew BJ, Byrd DA, Cherner M, Clifford DB, Cinque P, Epstein LG, Goodkin K, Gisslen M, Grant I, Heaton RK, Joseph J, Marder K, Marra CM, McArthur JC, Nunn M, Price RW, Pulliam L, Robertson KR, Sacktor N, Valcour V, Wojna VE (2007) Updated research nosology for HIV-associated neurocognitive disorders. Neurology 69:1789-99 
Beck AT, Steer RA, Brown GK (1987) Beck depression inventory manual, 2nd edn. The Psychological Corporation, Harcourt Brace \& Company, San Antonio, Texas

Benedict R, Schretlen D, Groninger L, Dobraski M (1996) Revision of the Brief Visuospatial Memory Test: studies of normal performance, reliability, and validity. Psychol Assess 8:145-153

Benedict R, Schretlen D, Groninger L, Dobraski M (1998) Hopkins Verbal Learning Test-Revised: normative data and analysis of inter-form and test-retest reliability. Clin Neuropsychol 12:43-55

Ciccarelli N, Fabbiani M, Di Giambenedetto S, Fanti I, Baldonero E, Bracciale L, Tamburrini E, Cauda R, De Luca A, Silveri MC (2011) Efavirenz associated with cognitive disorders in otherwise asymptomatic HIV-infected patients. Neurology 76:1403-9

Decloedt EH, Maartens G (2013) Neuronal toxicity of efavirenz: a systematic review. Expert Opin Drug Saf 12:841-6

Derogatis LR (1993) Brief symptom inventory (BSI): administration, scoring, and procedures manual, 3rd edn. National Computer Systems, Inc., Minneapolis, MN

Duff K (2012) Evidence-based indicators of neuropsychological change in the individual patient: relevant concepts and methods. Arch Clin Neuropsychol 27:248-61

Ellis RJ, Badiee J, Vaida F, Letendre S, Heaton RK, Clifford D, Collier AC, Gelman B, McArthur J, Morgello S, McCutchan JA, Grant I (2011) CD4 nadir is a predictor of HIV neurocognitive impairment in the era of combination antiretroviral therapy. AIDS 25:1747-51

Ettenhofer ML, Foley J, Castellon SA, Hinkin CH (2010) Reciprocal prediction of medication adherence and neurocognition in HIV/ AIDS. Neurology 74:1217-22

Gagliardo C, Murray M, Saiman L, Neu N (2013) Initiation of antiretroviral therapy in youth with HIV: a U.S.-based provider survey. AIDS Patient Care STDS 27:498-502

Gisslen M, Price RW, Nilsson S (2011) The definition of HIV-associated neurocognitive disorders: are we overestimating the real prevalence? BMC Infect Dis 11:356

Golden CJ, Freshwater SM (2002) The Stroop Color and Word Test: a manual for clinical and experimental uses. Stoelting Co., Wood Dale, Illinois

Grant I, Franklin DR Jr, Deutsch R, Woods SP, Vaida F, Ellis RJ, Letendre SL, Marcotte TD, Atkinson JH, Collier AC, Marra CM, Clifford DB, Gelman BB, McArthur JC, Morgello S, Simpson DM, McCutchan JA, Abramson I, Gamst A, Fennema-Notestine C, Smith DM, Heaton RK (2014) Asymptomatic HIV-associated neurocognitive impairment increases risk for symptomatic decline. Neurology 82:2055-62

Heaton RK, Franklin DR, Ellis RJ, McCutchan JA, Letendre SL, Leblanc S, Corkran SH, Duarte NA, Clifford DB, Woods SP, Collier AC, Marra CM, Morgello S, Mindt MR, Taylor MJ, Marcotte TD, Atkinson JH, Wolfson T, Gelman BB, McArthur JC, Simpson DM, Abramson I, Gamst A, Fennema-Notestine C, Jernigan TL, Wong J, Grant I (2011) HIV-associated neurocognitive disorders before and during the era of combination antiretroviral therapy: differences in rates, nature, and predictors. J Neurovirol 17:3-16

Lee L, Rand CS, Ellen JM, Agwu AL (2014) Factors informing HIV providers' decisions to start antiretroviral therapy for young people living with behaviorally acquired HIV. J Adolesc Health 55:358-65

Liang KY, Zeger SL (1986) Longitudinal data analysis using generalized linear models. Biometrika 73:13-22
McDonnell J, Haddow L, Daskalopoulou M, Lampe F, Speakman A, Gilson R, Phillips A, Sherr L, Wayal S, Harrison J, Antinori A, Maruff P, Schembri A, Johnson M, Collins S, Rodger A (2014). Minimal cognitive impairment in UK HIV positive men who have sex with men: effect of case definitions, and comparison with the general population and HIV negative men. J Acquir Immune Defic Syndr

Mitrushina M, Boone K, Razani J, D’Elia L (2005) Handbook of normative data for neuropsychological assessment. Oxford University Press, New York, NY

Nichols SL, Bethel J, Garvie PA, Patton DE, Thornton S, Kapogiannis BG, Ren W, Major-Wilson H, Puga A, Woods SP (2013) Neurocognitive functioning in antiretroviral therapy-naive youth with behaviorally acquired human immunodeficiency virus. J Adolesc Health 53:763-71

Norman MA, Moore DJ, Taylor M, et al (2011) Demographically corrected norms for African Americans and Caucasians on the Hopkins Verbal Learning Test-Revised, Brief Visuospatial Memory Test-Revised, Stroop Color and Word Test, and Wisconsin Card Sorting Test 64-Card Version. J Clin Exp Neuropsychol 33:793-804

Raudenbush SW, Bryk AS, Cheong YF, Congdon RT, Toit M (2011) HLM 7: hierarchical linear and nonlinear modeling [computer software]. Scientific Software International, Inc., Lincolnwood, IL

Reitan RM, Wolfson D (1993) The Halstead-Reitan neuropsychological test battery: theory and clinical interpretation, 2nd edn. Neuropsychology Press, Tucson, AZ

Robertson KR, Parsons TD, Sidtis JJ, et al. (2006) Timed Gait test: normative data for the assessment of the AIDS dementia complex. J Clin Exp Neuropsychol 28:1053-1064

Rudy BJ, Kapogiannis B, Bethel J, Wilson CM, Worrell C, Li S, Squires $\mathrm{K}$, Goodenow M, Agwu A, Sleasman J, Interventions. atATNfHA (2014) HIV therapy de-intensification to atazanavir/ritonavir (ATVr) monotherapy in adolescents/young adults maintain CD4 gains and VL suppression. Conference on Retroviruses and Opportunistic Infections (CROI), Boston

Strauss E, Sherman EMS, Spreen O (2006) A compendium of neuropsychological tests: administration, norms, and commentary. Oxford University Press, New York, NY

The Psychological Corporation (1997) WAIS-III/WMS-III technical manual. Psychological Corporation, San Antonio, Texas

Thompson MA, Aberg JA, Hoy JF, Telenti A, Benson C, Cahn P, Eron JJ, Gunthard HF, Hammer SM, Reiss P, Richman DD, Rizzardini G, Thomas DL, Jacobsen DM, Volberding PA (2012) Antiretroviral treatment of adult HIV infection: 2012 recommendations of the International Antiviral Society-USA panel. JAMA 308:387-402

Wallet MA, Rodriguez CA, Yin L, Saporta S, Chinratanapisit S, Hou W, Sleasman JW, MM. G (2010) Microbial translocation induces persistent macrophage activation unrelated to HIV-1 levels or T-cell activation following therapy. AIDS 24:1281-1290

Woods SP, Childers M, Ellis RJ, Guaman S, Grant I, Heaton RK (2006) A battery approach for measuring neuropsychological change. Arch Clin Neuropsychol 21:83-9

World Health Organization ASSIST Working Group (2002) The Alcohol, Smoking and Substance Involvement Screening Test (ASSIST): development, reliability and feasibility. Addiction 97:1183-1194 